\title{
Are Exchange Rates Really Free from Seasonality? An Exploratory Analysis on Monthly Time Series
}

\author{
Roberto Cellini* and Tiziana Cuccia
}

Department of Economics and Quantitative Methods, University of Catania, Corso Italia, 55- 95129 Catania, Italy

\begin{abstract}
This study deals with the seasonality of monthly time series of nominal exchange rates. Available literature overlooks seasonality in nominal bilateral exchange rates, and generally assumes that such rates are non-seasonal. We show that seasonality is absent in recent data, while it was present in selected cases from the Seventies and Eighties of the past century. We suggest that these pieces of evidence are consistent with the general equilibrium models of exchange rate determination.

JEL Classification: C22, F31.
\end{abstract}

Keywords: Seasonality, exchange rates.

\section{INTRODUCTION}

A huge body of theoretical and empirical literature deals with the pattern of exchange rates and their determinants at different frequencies. In this study, we focus on monthly time series. The available literature takes for granted that nominal exchange rates observed with a monthly frequency exhibit no seasonality and integration of order 1 (see, e.g., Jiménez-Martin and Flores de Frutos [1], and also Lastrapes [2] and Meese and Rogoff [3]).

The absence of seasonality in nominal exchange rates appears to be a sort of puzzle because their determinants show a great deal of seasonality if examined with a monthly frequency: consider, for instance, money supply, interest rates, consumption expenditures, and so on. The explanation generally provided is as follows. Agents know that fundamental macroeconomic variables present seasonal variation, but they like to limit the seasonality of exchange rates, if possible, to limit the noise in price signals in the economic system. Smoothing the dynamics of exchange rates and preventing exchange rates from fluctuating seasonally is possible thanks to appropriate behaviors in capital and good markets. Agents can thus reach welfareimproving results (Miron [4]; see also Grilli and Roubini [5] and Meese and Rogoff [6]). If so, we should expect that integration (and sophistication) of financial markets entail more limited seasonal variation of exchange rates, thanks to larger and larger possibility of financial smoothing.

To check this point we focus on selected bilateral exchange rates, observed over periods between January 1974 and December 2010. US dollar, British pound, Japanese yen, German mark, Italian lira, till to Euro, are considered. The choice to consider also national moneys (of the Euro area)

\footnotetext{
*Address correspondence to this author at the Department of Economics and Quantitative Methods, University of Catania, Corso Italia, 55- 95129 Catania - Italy, Tel: +39 095 7537728; Fax: +39 095 7537710;

E-mail: cellini@unict.it
}

that no longer exist is motivated by the interest in evaluating whether the birth of Euro represented a novelty, with respect to the experience of national currencies, as far as the seasonal pattern of exchange rate is concerned. The emerging evidence partially confirms our expectations.

In particular, we find that the exchange rates are far from being free from seasonality, broadly speaking. Seasonality is present in several cases, admittedly, concerning data from the decades of the Seventies and Eighties of the 20th century, whereas no seasonality emerges for more recent periods. This result could suggest that the increased financial integration of recent decades has indeed permitted a broader process of exchange rate smoothing over months.

\section{DATA AND TEST FOR SEASONALITY}

In what follows, we consider monthly time series of bilateral nominal exchange rates. Each observation is the monthly average value of daily rates as provided by the European Central Bank. ${ }^{1}$ For each of the considered monthly time series, we provide the following tests:

1. the $F$-test for evaluating the presence of stable seasonality, $F_{S}$; essentially, this test is based on the quotient of two variances: the between-month variance and the residual variance. The acceptance of the null hypothesis means that no seasonal variability is present in the data;

2. the Kruskall-Wallis statistic, $K$, which evaluates the equality of median values across different months (a value of this statistic falling into the rejection region means that median values are not constant across months);

3. the $F$-test for evaluating the presence of moving seasonality, $F_{M}$; this test (see, e.g., Higgison [7]) is applied to the sum of the seasonal and irregular

\footnotetext{
${ }^{1}$ All series are readily downloadable, for instance, from the website http://uif.bancaditalia.it/UICFEWebroot
} 
components of the time series (that is, the series without trend and cyclical components) and is based on the quotient of two variances, the variance between years and the residual variance. A test value falling in the rejection region means that the seasonalirregular component of the series is not stable across years.

All of the mentioned tests are computed by the X-12ARIMA program, which is the program provided by the US Census Bureau for evaluating (and disentangling) the seasonal components of time series, entering in a multiplicative or additive form. This program is among the most widely used in applied economic analyses. We also follow the suggested steps to evaluate and interpret the outcomes of testing procedures ${ }^{2}$.

If the $F_{S}$ test supports the null hypothesis of no stable seasonality, time series are considered not to be seasonal; generally, a consistent conclusion is also provided by the $K$ test, which shows that median values are constant across months. If, on the other hand, the $F_{S}$ test rejects the null of no seasonality, assuming stability, seasonality is present. In the latter case, two outcomes can happen as far as the $F_{M}$ test is concerned. If $F_{M}$ accepts the null of no moving seasonality, stable seasonality is present, and the conclusion of "identifiable stable seasonality present" is reached; the program can easily disentangle the seasonal component. On the contrary, a rejection of the absence by part of $F_{M}$ means that the seasonal component is moving over years, and the process of disentangling seasonality is difficult because the presence of moving seasonality can cause distortion. Depending on the combination of different tests, the program leads to the conclusion of "identifiable stable seasonality not present" or "identifiable stable seasonality probably not present"; the appropriate conclusion depends on the degree of moving seasonality relative to stable seasonality and has to be based on different combinations of tests. Such "negative" conclusions are problematic if the ultimate goal is to disentangle seasonality.

Measures of goodness of the de-seasonal procedure can be computed; for instance, the M7 statistic, which varies over the interval $[0,3]$, is widely used in applied economic research, and values lower than 1 indicate an accurate deseasonal procedure. An additional measure is represented by the Q statistic, which has to be lower than 1 to judge the deseasonal series as acceptable. Our main goal in this study, however, is not to derive de-seasonal time series but just to evaluate the presence of seasonal components. Thus, the presence of moving seasonality is a result that is important per se, even if it prevents disentangling the seasonal component in a correct and efficient way, and even if the diagnostic statistics of the de-seasonal procedure lead to judging the de-seasonal series as unsuitable. Here, we prefer to conclude that the series is "not-seasonal" (rather than, "identified stable seasonality is not present") in the case in

${ }^{2}$ The suggested steps are outlined, e.g., in documents downloadable from the US Census Bureau website www.census.gov, where the mentioned note by Higgison [7] is also provided, or from the SAS website, www.support.sas. com/documentation which both (i) the $F$-test on stable seasonality $F_{S}$ does not reject the absence of seasonality at the $0.1 \%$ significance level and (ii) the $K$ test does not reject the absence of seasonality at the $1 \%$ significance level. The consideration of such threshold levels of confidence is recommended by US Census Bureau office and is generally taken into account by current applied research. Results are presented in Table $1 .^{3}$

In the case of the exchange rate between the German mark (DEM) and US dollar (USD), if we split the sample into two sub-periods (before and after January 1990), stable seasonality is present and detectable (thanks to its stability) in the first sub-period (January 1974 to December 1989), whereas it is present but not detectable because of the instability over the second period (lines a).

In the cases of the Italian lira (LIT) vs USD and DEM, respectively, the evidence is substantially the same in different sub-periods (for this reason, the evidence concerning the different sub-periods is not provided by Table 1): monthly seasonality is present, but its instability does not permit it to be disentangled. (If we performed the test over the whole period, the conclusion would have been $B$, "Identifiable stable seasonality probably not present").

In the case of the exchange rate of the British pound (GBP) $v s$ USD, both the $F$-test and the $K$-statistic lead to acceptance of the absence of seasonality only for the subperiod 1991-2010, whereas in the previous considered period (1974-1990) the $K$-statistic is unable to support the absence of seasonality (however, the instability prevents its identification).

The inability of the tests to support the absence of seasonality, combined with significant instability of the seasonal component, applies also to the cases of the Euro (EUR) vs GBP and Japanese yen (JPY), respectively.

Finally, EUR/USD (1999-2010) and JPY/USD (over both periods, 1974-90 and 1991-2010) are cases in which both the $\mathrm{F}$ test and $\mathrm{K}$ statistic indicate that the data are not seasonal.

In sum, in seven cases, signs of seasonality (in the form of a multiplicative component in time series) are present, although in six out of these seven cases, seasonality is not detectable because of its instability. In one case, identifiable stable seasonality emerged: the DEM/USD exchange rate over the Seventies and Eighties.

In order to check for the reliability of our conclusions, additional tests are considered, always resting on an univariate time series analysis approach. Table 2 (Column 1), shows that seasonality takes the form of stochastic seasonality -and, more specifically, the form of seasonal unit root- in the cases of exchange rates LIT/USD, LIT/DEM (over the whole period, 1974-2001) and JPY/USD (over the sub-period 1974-90): in all these cases, the presence of a seasonal unit-root can not be rejected, according to the standard procedure à la Dickey, Hasza and Fuller [8]. On the

\footnotetext{
${ }^{3}$ Consider that, under the substantial point of view, the results are the same for the additional or multiplicative methods, and for the values in level or appropriate log transformation. In what follows, results refer to the series in plain level, and to the multiplicative method.
} 
Table 1. Tests on Seasonality

\begin{tabular}{|c|c|c|c|c|c|c|c|c|}
\hline & \multirow{2}{*}{$\begin{array}{c}\text { (1) } \\
\text { F on Stable } \\
\text { Seasonality }\end{array}$} & \multirow{2}{*}{$\begin{array}{l}(2) \\
K\end{array}$} & \multirow{2}{*}{$\begin{array}{c}\text { (3) } \\
F \text { on Moving } \\
\text { Seasonality }\end{array}$} & \multirow{2}{*}{$\begin{array}{c}\text { (4) } \\
\text { M7-Statistics } \\
\text { Q-Statistics }\end{array}$} & \multicolumn{4}{|c|}{$\begin{array}{c}(5) \\
\text { Conclusion }\end{array}$} \\
\hline & & & & & $\mathbf{A}$ & B & C & $\mathbf{D}$ \\
\hline $\begin{array}{c}\text { (a1) DEM/USD } \\
1974 \mathrm{~m} 01-1989 \mathrm{~m} 12\end{array}$ & $F_{11,180}=7.001 * *$ & $\begin{array}{l}K_{11}=67.720 \\
(\mathrm{p}=.0000) \#\end{array}$ & $F_{15,165}=2.105$ & $\begin{array}{c}M 7=0.97 \\
Q=0.73\end{array}$ & A & & & \\
\hline $\begin{array}{c}\text { (a2) DEM/USD } \\
\text { 1990m01-2001m12 }\end{array}$ & $F_{11,132}=4.661 * *$ & $\begin{array}{l}K_{11}=41.50 \\
(\mathrm{p}=.0000) \#\end{array}$ & $F_{11,121}=2.237$ & $\begin{array}{c}\mathrm{M} 7=1.21 \\
\mathrm{Q}=0.85\end{array}$ & & & $\mathrm{C}$ & \\
\hline $\begin{array}{c}\text { (b) LIT/USD } \\
1974 \mathrm{~m} 01-2001 \mathrm{~m} 12\end{array}$ & $F_{11,324}=4.842 * *$ & $\begin{array}{l}K_{11}=57.155 \\
(\mathrm{p}=.0000) \#\end{array}$ & $F_{27,297}=2.297 \S$ & $\begin{array}{c}\mathrm{M} 7=1.20 \\
\mathrm{Q}=0.90\end{array}$ & & & $\mathrm{C}$ & \\
\hline $\begin{array}{c}\text { (c) LIT/DEM } \\
\text { 1974m01-2001m12 }\end{array}$ & $F_{11,324}=7.454 * *$ & $\begin{array}{l}K_{11}=95.319 \\
(\mathrm{p}=.0000) \#\end{array}$ & $F_{27,297}=9.002 \S$ & $\begin{array}{c}\mathrm{M} 7=1.51 \\
\mathrm{Q}=0.92\end{array}$ & & & $\mathrm{C}$ & \\
\hline $\begin{array}{c}\text { (d1) GBP/USD } \\
\text { 1974m01-1990m12 }\end{array}$ & $F_{11,192}=2.087$ & $\begin{array}{l}K_{11}=26.897 \\
(\mathrm{p}=.0047) \#\end{array}$ & $F_{16,176}=2.577 \S$ & $\begin{array}{c}\mathrm{M} 7=2.09 \\
\mathrm{Q}=1.15\end{array}$ & & & C & \\
\hline $\begin{array}{c}\text { (d2) GBP/USD } \\
1991 \mathrm{~m} 01-2010 \mathrm{~m} 12\end{array}$ & $F_{11,228}=2.584$ & $\begin{aligned} K_{11} & =22.881 \\
(\mathrm{p} & =.0183)\end{aligned}$ & $F_{19,209}=5.888 \S$ & $\begin{array}{c}\mathrm{M} 7=2.19 \\
\mathrm{Q}=1.33\end{array}$ & & & & $\mathrm{D}$ \\
\hline $\begin{array}{c}\text { (e1) JPY/USD } \\
\text { 1974m01-1990m12 }\end{array}$ & $F_{11,192}=1.794$ & $\begin{array}{c}K_{11}=20.655 \\
(\mathrm{p}=.0373)\end{array}$ & $F_{16,176}=2.886 \S$ & $\begin{array}{c}\mathrm{M} 7=2.09 \\
\mathrm{Q}=1.02\end{array}$ & & & & $\mathrm{D}$ \\
\hline $\begin{array}{c}\text { (e2) JPY/USD } \\
1991 \mathrm{~m} 01-2010 \mathrm{~m} 12\end{array}$ & $F_{11,228}=1.128$ & $\begin{array}{c}K_{11}=14.138 \\
(\mathrm{p}=.2250)\end{array}$ & $F_{19,209}=3.523 \S$ & $\begin{array}{c}\mathrm{M} 7=2.79 \\
\mathrm{Q}=1.34\end{array}$ & & & & $\mathrm{D}$ \\
\hline $\begin{array}{c}\text { (f) EUR/GBP } \\
1999 \mathrm{~m} 01-2010 \mathrm{~m} 12\end{array}$ & $F_{11,132}=2.523^{*}$ & $\begin{array}{c}K_{11}=27.324 \# \\
(\mathrm{p}=.0041)\end{array}$ & $F_{11,121}=6.364 \S$ & $\begin{array}{c}\mathrm{M} 7=2.27 \\
\mathrm{Q}=1.13\end{array}$ & & & $\mathrm{C}$ & \\
\hline $\begin{array}{c}\text { (g) EUR/JPY } \\
1999 \mathrm{~m} 01-2010 \mathrm{~m} 12\end{array}$ & $F_{11,132}=2.934^{*}$ & $\begin{array}{c}K_{11}=31.291 \# \\
(\mathrm{p}=.0010)\end{array}$ & $F_{11,121}=5.706 \S$ & $\begin{array}{c}\mathrm{M} 7=2.03 \\
\mathrm{Q}=1.31\end{array}$ & & & $\mathrm{C}$ & \\
\hline $\begin{array}{c}\text { (h) EUR/USD } \\
\text { 1999m01-2010m12 }\end{array}$ & $F_{11,132}=0.979$ & $\begin{array}{c}K_{11}=10.651 \\
(\mathrm{p}=.4730)\end{array}$ & $F_{11,121}=1.965$ & $\begin{array}{c}\mathrm{M} 7=2.56 \\
\mathrm{Q}=1.29\end{array}$ & & & & $\mathrm{D}$ \\
\hline
\end{tabular}

Note: Column (0): reports bilateral exchange rate; DEM stays for Deutsche Mark, USD for US dollar, LIT for Italian Lira, JPY for Japanese Yen, GBP for UK pound, EUR for Euro. Column (1): *** means evidence of stable seasonality at the $1 \% / 0.1 \%$ level respectively.

Column (2): \# means evidence of seasonality at the $1 \%$ level.

Column (3): $\S$ means evidence of moving seasonality at the $1 \%$ level.

Column (4): A= Identifiable stable seasonality present.

$\mathrm{B}=$ Identifiable stable seasonality probably not present (according to the X-12 Arima procedure definition).

$\mathrm{C}=$ Identifiable stable seasonality not present (according to the $\mathrm{X}-12$ Arima procedure).

$\mathrm{D}=$ Not seasonal (both the $\mathrm{F}$ test at the $0.1 \%$ significance and $\mathrm{K}$ test at the $1 \%$ significance lead to accept the absence of seasonality assuming stability).

opposite, the presence of a seasonal unit-root has to be rejected in all the cases pertaining Euro, that is for the exchange rates of Euro vs all considered moneys; a similar result of absence of seasonal unit root applies to the rates GBP/USD (1974-2010) and JPY/USD (for the recent subperiod 1991-2010). In the cases in which seasonal unit roots appear to be absent, the seasonal dummy variables (capturing possible deterministic seasonality) are not significant, once the integration of order 1 of the series is taken into account (Table 2, Column 2): this leads to the conclusion that even this form of deterministic seasonality is absent in the cases at hand.

The results of Table 2 are broadly consistent with the evidence provided by Table 1; the only case in which a conflict could emerge concerns the DEM/USD exchange rate, for which the tests in Table 2 lead to exclude both the presence of stochastic seasonality (in the form of seasonal unit root) and the deterministic seasonality (in the form of seasonal dummies) over the whole time spam considered (and also in the sub-periods pre- and post- 1989), while Table 1 provides the evidence of detectable seasonal component (in the multiplicative form), for the first subperiod.
In our view, these pieces of evidence do not permit to conclude that monthly seasonality is not a problem for nominal exchange rates. However, and admittedly, it is true that the problem of monthly seasonality appears to diminish as more recent time periods are taken into consideration.

\section{COMMENTS AND RELATED LITERATURE}

Our results are fully consistent with the theoretical equilibrium models of exchange rate determination. For instance, the already mentioned article by Jimenez-Martinez and Flores de Frutos [1] modifies and extends the equilibrium model of Grilli and Roubini $[5]^{4}$ to incorporate explicitly seasonal dynamics, and namely seasonal taste shock in goods markets à la Miron [4]. In such a framework of general equilibrium, exchange rates are determined by production, monetary aggregates and asset returns, so that they should show seasonal patterns, unless agents are able to smooth the dynamics, thanks to appropriate investments in financial markets that impact on the relative returns home and abroad. The reason why agents are interested in smoothing the dynamics of variables is due to their convex 
preferences (i.e., concave utility function). The active behaviours of agents are able to lead exchange rates to equalize marginal utilities of currency across countries; however, such a result is possible only if transactions in financial markets are free, that is, obstacles to international capital mobility are absent or limited. Under this perspective, the evidence from our present study provides further support to the point made by Jimenez-Martin and Flores de Frutos [1]: they found that nominal exchange rates are not seasonal, focussing on five developed countries, after 1986; we document that nominal exchange rates' seasonality is present in selected cases of previous periods, when obstacles to international capital mobility were more relevant. ${ }^{5}$

Table 2. Tests on Stochastic and Deterministic Seasonality

\begin{tabular}{|c|c|c|}
\hline & $\begin{array}{c}\text { (1) } \\
\text { ADF on Seasonal } \\
\text { Unit Roots }\end{array}$ & $\begin{array}{c}\text { (2) } \\
\text { F on Seasonal } \\
\text { Dummies }\end{array}$ \\
\hline \hline (a) DEM/USD & -2.91 & $\mathrm{~F}=1.25(\mathrm{p}=0.25)$ \\
\hline (b) LIT/USD & $-1.50^{\wedge}$ & \\
\hline (c) LIT/DEM & $-1.76^{\wedge}$ & \\
\hline (d) GBP/USD & -4.13 & $\mathrm{~F}=0.71(\mathrm{p}=0.73)$ \\
\hline (e1) JPY/USD & $-1.32^{\wedge}$ & \\
(1975m01-1990m12) & & $\mathrm{F}=0.65(\mathrm{p}=0.78)$ \\
\hline (e2) JPY/USD & -4.75 & $\mathrm{~F}=1.31(\mathrm{p}=0.22)$ \\
\hline (1991m01-2010m12) & -2.35 & $\mathrm{~F}=1.03(\mathrm{p}=0.41)$ \\
\hline (f) EUR/GBP & $-2-40$ & $\mathrm{~F}=0.82(\mathrm{p}=0.69)$ \\
\hline (g) EUR/JPY & -2.27 & \\
\hline (h) EUR/USD & & \\
\hline
\end{tabular}

Note: Column (1): reports the ADF tests on the seasonal unit roots.

In particular, following Dickey, Hasza and Fuller [8], we perform the regression $\Delta_{12} y_{t}:=\left(y_{t}-y_{t-12}\right)=a+b y_{t-12}+c_{1}\left(\Delta_{12} y_{t}\right)_{-1}+c_{2}\left(\Delta_{12} y_{t}\right)_{-12}+\varepsilon_{t} \quad$ (where the terms containing $c_{1}$ and $c_{2}$ are inserted only if significant; we never inserted seasonal dummies, as long as they are not significant according to the appropriate F-test), and then we consider the $t$-statistics of coefficient $b$. The null hypothesis is $b=0$ which means that the seasonal root is present. Appropriate critical values of $t$ are provided in Dickey, Hasza and Fuller [8]; hat denotes that ADF test values can not reject the null (i.e., the presence of the seasonal unit root can not be rejected).

Column (2): reports the $F$ tests on the significance of 11 seasonal dummies $(D U M)$ in the regression: $\Delta y_{t}:=\left(y_{t}-y_{t-1}\right)=a+b y_{t-1}+c_{1}\left(\Delta_{1} y_{t}\right)_{-1}+c^{\prime} D U M+\varepsilon_{t}$. Reported values are never significant at the $5 \%$ level.

We are well aware that more sophisticated techniques are available to examine seasonality, and different (and more complex) concepts of seasonality have been developed consistently. For instance, a line of research bases on

\footnotetext{
${ }^{5}$ Following a suggestion of a referee, we have checked whether recessions have an impact on the seasonality of exchange rates. In each regression considered for Column (1) and Column (2) of Table 2, we have inserted a dummy variable, if at least one of the considered countries was in a recession (yearly data). Such dummy variables are never significant in regressions concerning Column (2), while are sometimes significant in regressions concerning Column (1). In the case in which they are significant, however, the evidence concerning the seasonal unit root never changes, as compared to the specification without the dummy for recession. Though we are aware that this regression design is very simple, we conclude that there is no evidence for the fact that recession have an impact on the seasonal patterns of nominal exchange rates. This is consistent with the fact that recessions have not entailed -in the time spans under scrutiny- relevant modification of financial integration.
}

"seasonal fractional integration" issue, which represents an extension of the seasonal unit root approach (Gil-Alana [10], Ferrara and Guegan [11]; see Gil-Alana [12] for an application to exchange rates). Moreover, non linear models of seasonality are available, or models with multiple periodic processes capturing seasonality (see, Ghyser and Osborn [13, Chapters 6 and 7]). Nevertheless, we prefer to focus on the simplest issue of seasonality (and to the corresponding simple testing design), since it permits to unravel the differences across decades in a framework as simple as possible, and to make clear that the degree of seasonality in nominal exchange rates decreases as financial integration increases.

A final remark is in order with respect to the findings of a recent study of Ho [14], concerning the seasonality of real exchange rates: Ho takes into consideration a panel of data with quarterly frequency, and provides evidence documenting the presence of a great deal of seasonality in real exchange rates. ${ }^{6}$ Our present study suggests that the source of seasonality in real exchange rates can be found in the nominal rates, not only in the price indices, especially if data cover periods or countries characterized by limited international capital mobility.

\section{CONCLUDING REMARKS}

In this study we have documented that a variety of different results emerge from the real world evidence, as far as the seasonality of monthly time series of bilateral nominal exchange rate is concerned. In our view, the provided evidence lends itself to a clear interpretation: seasonality is present during less recent periods, while, in more recent periods, the evidence of seasonality is absent according to widely accepted criteria. In particular, we have documented that in the Euro area, the national moneys that no longer exist, showed a great deal of seasonality, whereas the Euro exchange rates appear to be non-seasonal. However, the explanation we provide is not connected with the fact that Euro covers a wider area than the (former) national currencies; rather, we are inclined to explain this evidence with the growing financial integration, consistent with the reduction over time of the degree of seasonality for exchange rates like that involving yen, dollar and pound.

From this perspective, an interpretation of the "disappearance of seasonality" can be proposed, fully consistent with the general equilibrium models of exchange rate determination: determinants of exchange rates are seasonal -let us think of income, consumption expenditures, money demand, interest rates. However, when possible, agents smooth the seasonal fluctuations of exchange rates. This is easier in a more financially integrated world.

\footnotetext{
${ }^{6}$ Consistent with this view is Gil-Alana [11], who takes a fractional seasonal integration approach to analyse real effective exchange rate of Japan, and shows that the monthly time are integrated of order 1 , and seasonal movements are less important though not insignificant. Analogous results are provided, in a different framework, by Lastrapes [2].
} 


\section{REFERENCES}

[1] Jiménez-Martin JA, Flores de Frutos R. Seasonal fluctuations and equilibrium models of exchange rate. Appl Econ 2009; 41: 263552.

[2] Lastrapes WD. Sources of fluctuations in real and nominal exchange rates. R Econ Stat 1992; 74: 530-39.

[3] Meese RA, Rogoff K. Empirical exchange rate models of the Seventies: do they fit out the sample? J Int Econ 1983; 14: 3-24.

[4] Miron JA. Seasonal fluctuations and the life cycle - permanent income model of consumption. J Pol Econ 1986; 94: 1258-79.

[5] Grilli V, Roubini N. Liquidity and exchange rates. J Int Econ 1992; 32: 339-52.

[6] Meese R, Rogoff $\mathrm{K}$. What is real? The exchange rate - interest differential relation over the modern floating rate period. J Fin 1988; 43: 933-48.

[7] Higgison J. An F test for the presence of moving seasonality, mimeo 1975; downloadable from the US Census Bureau website, www.census.gov [Accessed: May 2011].
[8] Dickey DA, Hasza DP, Fuller WA. Testing for unit roots in seasonal time series. J Am Stat Assoc 1984; 79: 355-67.

[9] Cole H, Obstfeld M. Commodity trade and international risk sharing: how much do financial markets matter? J Mon Econ 1991; 28: 3-24.

[10] Gil-Alana LA. Deterministic seasonality versus seasonal fractional integration, Facultad de ciencias economicas y empresariales Universidad de Navarra working paper 07/2004.

[11] Ferrara L, Guegan D. Fractional seasonality: models and application to economic activity in the Euro area. working paper 2006; Eurostat (download from http://epp.eurostat.ec.europa.eu)

[12] Gil-Alana LA. Seasonal and non seasonal long memories effects in Japanese reale effective exchange rates. J Jpn Intern Econ 2006; 20: 87-98.

[13] Ghysels E, Osborn DR. The Econometric Analysis of Seasonal Time Series. Cambridge UK: Cambridge University Press 2001.

[14] Ho TW. Testing seasonal mean-reversion in the real exchange rates: an application of nonlinear IV estimantor. Econ Lett 2008; 99: $314-6$

(C) Cellini and Cuccia; Licensee Bentham Open.

This is an open access article licensed under the terms of the Creative Commons Attribution Non-Commercial License (http://creativecommons.org/licenses/by$\mathrm{nc} / 3.0 /$ /) which permits unrestricted, non-commercial use, distribution and reproduction in any medium, provided the work is properly cited. 